\title{
Hyaluronidase (Hyalase): a useful addition in haematoma block?
}

\author{
N J London, F A Osman, K Ramagopal, S F Journeaux
}

\begin{abstract}
Objective-To investigate whether hyaluronidase (Hyalase) is a useful and justified addition to haematoma block for pain relief.

Methods-The study was a randomised double blind trial of 33 consecutive patients attending the accident and emergency department for manipulation of distal radius fracture under haematoma block. Control patients received $1 \%$ lignocaine; the treatment group received $1 \%$ lignocaine plus 1500 IU hyaluronidase. Manipulation occurred 10 minutes after instituting the block.

Results-16 patients received hyaluronidase, 17 received lignocaine only. One patient with unsuccessful manipulation was excluded. There was no significant difference between the two groups for any of three methods of pain assessment ( $P>0.05$, Mann Whitney).

Conclusions-The addition of hyaluronidase does not increase the efficacy of the haematoma block when 10 minutes are allowed to elapse before manipulation, and the increased cost of adding (and risk of allergy) is not justified by any theoretical increased speed of analgesia.

$(\mp$ Accid Emerg Med 1996;13:337-338)
\end{abstract}

Key terms: hyaluronidase; lignocaine; haematoma block

The use of haematoma block for the manipulation of distal radius fractures has increased over recent years with the reduction in anaesthetic services in accident and emergency (A\&E) departments. The advantages of this method of anaesthesia include speed, safety, and minimal inconvenience to the patient. ${ }^{1}$

Some centres routinely inject hyaluronidase (Hyalase) with the local anaesthetic in an attempt to increase the speed and efficacy of the block, although evidence that it does this is limited. ${ }^{2}$ Hyaluronidase is an enzyme which breaks down the intracellular matrix of connective tissue and is used to enhance the permeation of local anaesthetic in a variety of situations. $^{3}$ There have, however, been recorded cases of allergic reactions to hyaluronidase and caution has been advised in atopic individuals. ${ }^{4}$ This study, in the form of a randomised, double blind trial, investigates whether hyaluronidase is a useful and justified addition to haematoma block.

\section{Methods}

The protocol was approved by the local ethics committee and fully informed consent was
Table 1 Group details

\begin{tabular}{lll}
\hline & $\begin{array}{l}\text { Lignocaine with } \\
\text { hyaluronidase }(n=14)\end{array}$ & $\begin{array}{l}\text { Lignocaine only } \\
(n=17)\end{array}$ \\
\hline $\begin{array}{lll}\text { Sex ratio (F:M) } \\
\begin{array}{c}\text { Mean age (years) } \\
\text { (SE) }\end{array}\end{array}$ & $13: 1$ & $17: 0$ \\
\hline
\end{tabular}

obtained from each patient. Thirty three consecutive patients, with distal radius fractures which were considered suitable for manipulation under haematoma block, were randomly allocated to receive $1 \%$ lignocaine or $1 \%$ lignocaine with 1500 IU hyaluronidase (Hyalase; CP Pharmaceuticals). The anaesthetic mixture was not known to either patient or clinician. Eight millilitres were injected into the radius fracture haematoma and $2 \mathrm{ml}$ around the ulna styloid. The manipulation was performed after a period of 10 minutes had elapsed by one of two experienced clinicians.

Assessment of manipulation pain included verbal rating scores ( 1 to 5) of patient's satisfaction with pain relief (five categories: poor, fair, adequate, good, and excellent) and the severity of any pain experienced (five categories: absent, mild, discomforting, distressing, and excruciating). The patients also quantified their pain using a $10 \mathrm{~cm}$ visual analogue scale (VAS), taking zero as no pain and 10 as worst imaginable pain. ${ }^{5}$ Statistical analysis of results was by the Mann Whitney $U$ test and each method of pain assessment was examined separately.

\section{Results}

Sixteen patients received hyaluronidase, of whom one was excluded from analysis due to an inability to comprehend the VAS and one excluded due to an unsuccessful manipulation $(n=14) ; 17$ received lignocaine only. Demographic details are summarised in table 1. All the fractures had 'Colles'-type deformities and. on analysis the severity of the fractures was comparable for the two groups. There were no side effects noted in either group. Results for each of the three methods of pain assessment are shown in table 2 . There was no significant difference between the two groups for any of the three methods of pain assessment (P > 0.05, Mann Whitney).

\section{Discussion}

Haematoma block is a useful method of anaesthesia for reduction of appropriate distal radius fractures in $A \& E$ departments. ${ }^{1}$ The acceptability by the patient of this method of pain control is confirmed by all three pain assess- 
Table 2

Results of pain assessment scores - median

\begin{tabular}{lll}
\hline & $\begin{array}{l}\text { Lignocaine with } \\
\text { hyaluronidase } \\
(n=14)\end{array}$ & $\begin{array}{l}\text { Lignocaine only } \\
(n=17)\end{array}$ \\
\hline $\begin{array}{l}\text { Satisfaction with } \\
\text { pain control }\end{array}$ & $\begin{array}{l}\text { Good (adequate - } \\
\text { excellent) }\end{array}$ & $\begin{array}{l}\text { Good (fair - } \\
\text { excellent) }\end{array}$ \\
$\begin{array}{l}\text { Severity of pain } \\
\text { Discomforting } \\
\text { (mild - } \\
\text { discomforting) }\end{array}$ & $\begin{array}{l}\text { discomforting) } \\
\text { discont }\end{array}$ \\
$\begin{array}{c}\text { Visual analogue } \\
\text { scale }\end{array}$ & $2(0-3)$ & $2(0-5)$
\end{tabular}

ments performed in this study. The addition of hyaluronidase does not increase the efficacy of the block when 10 minutes were allowed to elapse before manipulation, and the increased cost of adding hyaluronidase (and the risk of allergy) is not justified by any theoretical increased speed of analgesia.

1 Case RD. Haematoma block a safe method of reducing Colles fractures. Injury 1985;16:469-70.

2 Thorpe IN. Procaine with hyaluronidase as a local anaesthetic. Lancet 1951:i:210-1

3 Watson D. Hyaluronidase. Br $\mathcal{F}$ Anaesth 1993;71:422-5.

4 Sakomoto K, Nagai H, Kada A. Role of hyaluronidase in immediate hypersensitivity reactions. Immunopharmacology 1980;2:139-46.

5 Banos JE, Bosche F, Canellas M, Bassols A, Ortega F, Bigorra $\mathrm{J}$. Acceptability of visual analogue scales in the clinical setting: a comparison with verbal rating scales in postoperasetting: a comparison with verbal rating scales in postopera-
tive pain. Methods Find Exp Clin Pharmacol 1989;11:123-7.

\section{Referees for the Fournal of Accident $\mathcal{E}$ Emergency Medicine}

All papers submitted for publication in the Journal of Accident \& Emergency Medicine undergo peer review. As a result of the continuing rise in the number of papers received the Journal seeks additional referees.

This is an interesting and stimulating activity. The Editorial Office ensures that the workload for referees is not onerous and guidelines are provided to allow a structured critique of each paper. Referees are expected to return comments within three weeks of receipt of the manuscript.

Please contact the Editor, Journal of Accident \& Emergency Medicine at BMA House, Tavistock Square, London WC1H 9JR, telephone 0171-383-6795, fax. 0171-383-6668, stating your present appointment and any areas of special expertise. Reviewers are particularly welcome from other specialties with an interest in Emergency Medicine and from outside the U.K. 